\title{
Outcomes of a prospective multi-center trial of a second- generation composite mesh for open ventral hernia repair
}

\author{
E. M. Hanna $\cdot$ J. F. Byrd $\cdot$ M. Moskowitz $\cdot$ \\ J. W. F. Mann - K. T. Stockamp • G. N. Patel • \\ M. A. Beneke $\cdot$ K. Millikan $\cdot$ D. A. Iannitti
}

Received: 5 March 2012/ Accepted: 1 March 2013/Published online: 24 March 2013

(C) The Author(s) 2013. This article is published with open access at Springerlink.com

\begin{abstract}
Purpose Composite mesh prostheses incorporate properties of multiple materials for use in open ventral hernia repair (OVHR). This study examines clinical outcomes in patients who underwent OVHR with a polypropylene/ expanded polytetrafluoroethylene (ePTFE) composite graft containing a novel polydioxanone (PDO) absorbable ring to facilitate placement and graft positioning.

Methods Data were prospectively collected on consecutive patients undergoing OVHR using a synthetic composite mesh. Seven centers enrolled patients during the study period. All patients underwent a standardized surgical procedure consisting of OVHR with sublay intraperitoneal placement of mesh. Mesh fixation was accomplished with peripheral tacks and transfascial sutures.
\end{abstract}

E. M. Hanna · J. F. Byrd · D. A. Iannitti ( $\square)$

Department of General Surgery, Division of Hepato-Pancreato-

Biliary Surgery, Carolinas Medical Center, 1025 Moorehead

Medical Drive, Suite 300, Charlotte, NC 28204, USA

e-mail: David.Iannitti@carolinashealthcare.org

M. Moskowitz

Gaston Memorial Hospital, Gastonia, NC, USA

J. W. F. Mann

Medical Park Hospital, Winston-Salem, NC, USA

K. T. Stockamp

Sacred Heart Health System, Pensacola, FL, USA

G. N. Patel

St. Francis Medical Center, Peoria, IL, USA

M. A. Beneke

Sutter General Hospital, Sacramento, CA, USA

K. Millikan

Rush University Medical Center, Chicago, IL, USA
Results One hundred and nineteen patients underwent OVHR with the composite mesh. Average age was 55.8 years; there were $71(59.7 \%)$ females and 48 $(40.3 \%)$ males with mean BMI of $33.5 \pm 7.1 \mathrm{~kg} / \mathrm{m}^{2}$. One hundred and two $(85.7 \%)$ patients presented with primary ventral hernias. Mean defect size was $13.6 \mathrm{~cm}^{2}$, and mean mesh size was $113.6 \mathrm{~cm}^{2}$. Most patients $(67 \%)$ were discharged the day of surgery. Twelve patients (10.1\%) experienced complications in the perioperative time period primarily consisting of seroma (4.2\%) and ileus (1.7\%). Two patients required reoperation and mesh removal in the early postoperative period for infection and herniorrhaphy site pain, respectively. There was a decline in pain and movement limitation scores between baseline and 1-year follow-up. Six-month $(n=109)$ and twelve-month $(n=99)$ follow-up revealed no hernia recurrences $(95 \%$ CI 0-3\%, and 0-4\%, respectively).

Conclusions The use of this second-generation composite mesh was associated with no hernia recurrences and a low complication rate after open ventral hernia repair.

Keywords Ventral hernia repair - Composite mesh . Outcomes

\section{Introduction}

Ventral hernias are commonly encountered by surgeons with an incidence of up to $20 \%$ following laparotomy [13]. Surgical decision-making for the repair of ventral and incisional hernias includes the type and technique of repair to be performed and if prosthetic mesh material is to be used, what type of material is best suited in order to provide the most optimal repair. While the use of mesh for abdominal wall reconstruction has significantly reduced 
hernia recurrence as compared to primary repair [4-6], there is no consensus as to which mesh provides the best possible repair. As a result, a tremendous amount of research has gone into the development of new and different prosthetic grafts for use in ventral hernia repair, with each new innovation attempting to reduce detriments seen with its predecessor.

In this study, we performed a post-market assessment of the clinical and procedural outcomes of open ventral hernia repair performed using a second-generation composite graft. The primary endpoint was the evaluation of hernia recurrence with secondary endpoints including perioperative, short-term and long-term complications, changes in quality of life as assessed by the Carolinas Comfort Scale survey [7], and procedure time.

\section{Methods}

Institutional Review Board approval was obtained and data were prospectively collected on consecutive patients undergoing open ventral hernia repair using the Ventrio ${ }^{\mathrm{TM}}$ Hernia Patch (C.R. Bard; Davol Inc. Warwick, RI). Seven sites contributed to patient accrual: Carolinas Medical Center, Charlotte, NC; Gaston Memorial Hospital, Gastonia, NC; Medical Park Hospital, Winston-Salem, NC; Sacred Heart Health System, Pensacola, FL; St. Francis Medical Center, Peoria, IL; Sutter General Hospital, Sacramento, CA; and Rush University Medical Center, Chicago, IL. Inclusion criteria were the following: age $\geq 18$ years, ability to undergo study procedure and provide informed consent, and presence of a ventral hernia requiring open surgical repair. Exclusion criteria included participation in another drug or device study, life expectancy $<2$ years, clinical symptoms of infected hernia site, or evidence of contaminated or clean contaminated fields. Demographic, operative, perioperative, and postoperative data for each patient were collected at each participating institution.

Adverse events in this study were defined as any undesirable clinical event occurring in the abdominal wall, involving abdominal organs, or judged to be related to the surgical procedure or the Ventrio ${ }^{\mathrm{TM}}$ Hernia Patch. Adverse events were further divided according to their relationship to the device or surgical procedure performed with subcategories defined as definitely, possible or not related to the device or procedure. Relationship of the adverse event to the device or surgical procedure was determined by the operating surgeon in regard to their respective patients. Adverse events were also classified by the intensity experienced by the subject as mild, moderate, or severe. Mild events included awareness of a sign or symptom that does not interfere with the subject's activity and is resolved without treatment or sequelae. Moderate events may interfere with the subject's activity and require additional treatment or intervention while severe events definitely cause significant discomfort to the subject and require additional treatment with additional sequelae.

Perioperative adverse events occurred within 14 days of the hernia repair. Early postoperative events occurred between 15 days and 6 months following surgery, and late postoperative events occurred greater than 6 months after hernia repair.

Patient follow-up was reported at postoperative visits on the following time points: 2 weeks, 6 months, and 1 year with defined days during which patients were to report for each of the follow-up visits. At each office visit, an interim history and physical exam were performed by the operating surgeon or a designated assistant. At each postoperative visit and at the initial preoperative evaluation and screening, patients were given a copy of the Carolinas Comfort Scale (CCS) to assess quality of life characteristics related to their hernia and postoperatively following hernia repair with mesh. Specifically, the CCS survey evaluates quality of life in three areas: pain, sensation of mesh, and movement limitation during various activities. In addition, patients were assessed at each postoperative visit via short questionnaire for time to return to normal activities of daily living, time to return to strenuous or vigorous activity, and if working, their ability to return to work. If at any time, a patient was suspected by the operating surgeon to have a recurrent hernia or to undergo imaging and a recurrent hernia visualized, the investigator was to report the findings immediately to the study coordinator.

Descriptive statistics were used to calculate quantitative data including mean values, standard deviations, and proportions. Frequency and proportion tables were used to summarize the qualitative data. Defect size was calculated by area of an ellipse: $\pi \times($ Length $/ 2 \times \mathrm{Width} / 2)$. For analysis of results of Carolinas Comfort Scale assessment, descriptive statistics were used to calculate mean values with $95 \%$ confidence intervals generated to analyze significance of the mean. CCS questionnaires were scored with the following parameters: if more than two questions were left unanswered on any questionnaire (except sensation of mesh scale at the baseline visit), the whole questionnaire was not used in analysis. If less than or equal to two questions were missing within any of the three scales, the missing values were replaced by the mean of the remaining items of the scale. Scores were assigned numerical values corresponding to patient responses; for example, no symptoms were assigned score of 0 and disabling symptoms were assigned a score of 5. Mean scores and changes from baseline over all patients were calculated for each question. Mean of the mean values for sensation of mesh, pain, and movement limitation scales were calculated. No baseline scores were reported for sensation of mesh. 


\section{Operative procedure}

The standard technique used for this surgical repair was discussed by the participating surgeons and agreed upon prior to beginning the study. This technique involved an abdominal incision made overlying the area of the hernia defect. Dissection was performed to the hernia sac which was carefully inspected to evaluate for incarceration. The hernia sac was opened and the peritoneal cavity entered. If the hernia sac was to be used for graft coverage, it was not resected. Dissection of the surrounding subcutaneous tissues was minimized. Adhesions were taken down from the undersurface of the abdominal wall. Defect size was measured as the greatest width from edge to edge. An inspection for multiple hernia defects was performed with measurements of all defect sizes recorded for study purposes. Surgeons were instructed to clear a plane of at least $5 \mathrm{~cm}$ around the total defect perimeter. An appropriately sized Ventrio $^{\mathrm{TM}}$ Hernia Patch was determined by the measurement of the defect size with an additional minimum of $3 \mathrm{~cm}$ of overlap in all directions. The mesh was then placed through the fascial defect and centered on the defect from behind to ensure a wide overlap.

A hernia mesh tacker was then used to tack the periphery of the mesh to the abdominal wall to facilitate fixation and stabilization of the mesh for easier placement of transfascial sutures. The technique of tacking the mesh involved placing the tacker through the slit in the center of the anterior layer of the polypropylene mesh surface. The tacker was then advanced laterally to the periphery of the mesh while the assistant was retracting the abdominal wall medially. The tacker was used to tack the graft at $1-$ to $2-\mathrm{cm}$ intervals to the abdominal wall, circumferentially. After placing the tacks, sutures were placed through the anterior layer of mesh and through the posterior abdominal wall in a transfascial fashion for additional fixation. The number of transfascial sutures placed varied with the size of the defect, although sutures were generally placed in each of the four quadrants and every $2-3 \mathrm{~cm}$ apart. When feasible, the fascia was closed overlying the graft to achieve soft-tissue coverage over the mesh. Finally, the abdominal incision was closed, and drains were selectively placed at the discretion of the operating surgeon.

For each patient, one Ventrio ${ }^{\mathrm{TM}}$ Hernia Patch was used to cover all hernia defects with adequate overlap according to the operating surgeon. For multiple defects, a total defect size was calculated to determine the size of mesh utilized for repair. In patients with recurrent hernia and prior mesh repair, the previous mesh was left in place and the new mesh placed in a sublay position to the old mesh.

\section{Results}

A total of 120 patients were consented in the study. One patient elected to withdraw from the study after consent was obtained but prior to undergoing surgery for a final enrollment of 119 patients who underwent open ventral hernia repair with the Ventrio ${ }^{\mathrm{TM}}$ Hernia Patch. No patients underwent concomitant procedures. All patients received prophylactic antibiotics at the time of surgery. Follow-up data were collected from 109 patients $(92 \%)$ at 6 months and 99 patients $(83 \%)$ at 1 year following surgery. The average age was $55.8 \pm 13.6$ years, and $59.7 \%$ of patients were female and $40.3 \%$ of patients were male. Most patients underwent open ventral hernia repair on an outpatient basis or were discharged within $24 \mathrm{~h}$ of surgery. Medical history was significant for prior abdominal surgeries in $78.2 \%$ of patients, $22.7 \%$ were current smokers, and $21.0 \%$ had diabetes. Table 1 lists patient demographics and operative details. In this series, 102 patients $(85.7 \%)$ presented with primary ventral hernias and 17 patients $(14.3 \%)$ had recurrent hernias with a range of 1-4 previous repairs. Of the patients presenting with recurrent hernias, 10 patients had prior mesh repairs (Table 2).

Table 1 Patient characteristics and operative details

\begin{tabular}{lrrlll}
\hline Variable & Mean & SD & Median & Minimum & Maximum \\
\hline Age (years) & 55.8 & 13.6 & 57 & 26 & 89 \\
BMI $\left(\mathrm{kg} / \mathrm{m}^{2}\right)$ & 33.5 & 7.1 & 32.9 & 21 & 51.5 \\
$\begin{array}{l}\text { Fascial defect size } \\
\quad\left(\mathrm{cm}^{2}\right)\end{array}$ & 13.6 & 11.1 & 9.4 & 0.8 & 56.5 \\
$\begin{array}{l}\text { Mesh size }\left(\mathrm{cm}^{2}\right) \\
\begin{array}{l}\text { Operative time } \\
\quad(\text { min) }\end{array}\end{array}$ & 113.6 & 52.7 & 121.0 & 45.4 & 192.9 \\
$\begin{array}{l}\text { Incision length } \\
\quad(\mathrm{cm})\end{array}$ & 7.5 & 2.7 & 7.0 & 3.0 & 15.0 \\
$\begin{array}{l}\text { Length of stay } \\
\quad \text { days) }\end{array}$ & 0.7 & 1.5 & 0.0 & 0.0 & 11.0 \\
\hline
\end{tabular}

Table 2 Primary and recurrent hernia repairs performed in 119 patients

\begin{tabular}{lrr}
\hline Type of hernia & $\mathrm{n}$ & $\%$ \\
\hline Primary & 102 & 85.7 \\
Recurrence & 17 & 14.3 \\
1st & 12 & 10.1 \\
2nd & 3 & 2.5 \\
3rd & 1 & 0.8 \\
4th & 1 & 0.8 \\
Previous mesh repair & 10 & 8.4 \\
No previous mesh repair & 7 & 5.9 \\
\hline
\end{tabular}


The Ventrio ${ }^{\mathrm{TM}}$ Hernia Patch was used during all surgeries and secured to provide adequate overlap at the periphery of each fascial defect; minimum mesh overlap was defined by the study criteria as not less than $3 \mathrm{~cm}$. All surgeons utilized the previously described surgical technique for graft placement and fixation. For this series, the average incision length was $7.5 \pm 2.7 \mathrm{~cm}$. The composite mesh is commercially available in a range of sizes in both circular and oval shapes. During the enrollment period, five sizes were available with the largest size being the large oval. Twenty-two patients in this series were identified to have multiple defects for a total of 148 defects repaired in all 119 patients enrolled. The mean fascial defect size was $13.6 \pm 11.1 \mathrm{~cm}^{2}$ (median defect size $9.4 \mathrm{~cm}^{2}$, range $0.8-56.5 \mathrm{~cm}^{2}$ ). While a variety of graft sizes were used in this study, the mesh size most frequently used was medium oval $(n=40)$ followed by large oval $(n=28)$. The least frequently used was large circle $(n=9)$. Only one mesh was used in each patient including patients with multiple defects. The majority of patients with multiple defects presented with a primary hernia (90.9\%), only two patients had recurrent hernia and multiple defects. The average operative time was $42.8 \pm 19.8 \mathrm{~min}$. Eight patients had drains placed at the discretion of the surgeon. In the majority of patients, meshes were fixed at the perimeter with an absorbable or permanent mechanical tack fixation device. In addition, the mesh was fixed in the center with transfascial sutures $3 \mathrm{~cm}$ apart using either absorbable or permanent sutures (Table 3). The fascia was re-approximated at the midline for mesh coverage in $65.5 \%$ of patients. The remaining patients underwent midline closure using either hernia sac, muscle, subcutaneous tissue or a combination of components.

During the study period, there were 20 patients for which 1-year follow-up could not be obtained. There was one patient death that occurred at approximately 6 months following surgery. The patient had a known recurrent

Table 3 Method of mesh fixation used in 119 patients

\begin{tabular}{llrr}
\hline & Fixation method & \multicolumn{1}{c}{$n$} & \multicolumn{1}{c}{$\%$} \\
\hline Perimeter fixation & Mechanical & 113 & 95.0 \\
& Suture & 3 & 2.5 \\
& Not done & 3 & 2.5 \\
Off-center fixation & Mechanical & 4 & 3.4 \\
& Suture & 115 & 96.6 \\
\multirow{3}{*}{ Method of midline closure } & Not done & 0 & 0.0 \\
& Fascia & 78 & 65.5 \\
& Hernia sac & 35 & 29.4 \\
& Other & \\
& & 6 & 5.0 \\
\hline
\end{tabular}

$\overline{{ }^{a} \text { Either combination of fascia and hernia sac, subcutaneous tissue, or }}$ muscle closed at midline metastatic pancreatic neuroendocrine tumor and expired at an outlying facility. The cause of death was due to multisystem organ failure and not related to the study procedure or device. Twelve patients were lost to follow-up. Four patients moved to a non-study participating location or were unable to complete the study for other non-study related conditions, and two patients withdrew from the study following a complication and did not wish to comply with follow-up requirements. One patient did not complete follow-up due to an investigator and patient decision to remove the device after continued herniorrhaphy site pain.

Table 4 lists patient complications by varying postoperative time periods. Twelve patients experienced 13 complications in the perioperative period, which includes 0-14 days postoperatively. The majority of these were mild with seroma and postoperative ileus being the most frequent. One patient complained of significant herniorrhaphy site pain, as noted earlier, which began postoperatively and extended through multiple follow-up visits. At 6-month follow-up, the patient continued to have suture site pain and requested to have the mesh removed with primary closure of the defect. Following mesh removal, the patient's pain resolved; the primary cause of pain was

Table 4 Complications experienced by patients at varying time intervals

\begin{tabular}{|c|c|c|c|}
\hline & $\begin{array}{l}\text { Perioperative } \\
(n=119)^{\mathrm{a}}\end{array}$ & $\begin{array}{l}<6 \text { months } \\
(n=109)\end{array}$ & $\begin{array}{l}6-12 \text { months } \\
(n=99)\end{array}$ \\
\hline \multicolumn{4}{|l|}{ Major complications } \\
\hline Death & 0 & $\begin{array}{c}1(<1 \%) \\
\text { Cancer } \\
\text { related }\end{array}$ & 0 \\
\hline $\begin{array}{l}\text { Wound infection } \\
\text { (non-mesh infection) }\end{array}$ & $1(<1 \%)$ & 0 & 0 \\
\hline $\begin{array}{l}\text { Wound/mesh } \\
\text { infection }\end{array}$ & 0 & $1(<1 \%)$ & 0 \\
\hline Abdominal abscess & 0 & $1(<1 \%)$ & 0 \\
\hline $\begin{array}{l}\text { Pain at repair } \\
\text { requiring } \\
\text { reoperation }\end{array}$ & $1(<1 \%)$ & 0 & 0 \\
\hline Hernia recurrence & 0 & 0 & 0 \\
\hline \multicolumn{4}{|l|}{ Minor complications } \\
\hline Seroma & $5(4.2 \%)$ & $1(<1 \%)$ & 0 \\
\hline Hematoma & $1(<1 \%)$ & & \\
\hline Urinary retention & $1(<1 \%)$ & 0 & 0 \\
\hline $\begin{array}{l}\text { Hypoesthesia at } \\
\text { right thigh }\end{array}$ & $1(<1 \%)$ & 0 & 0 \\
\hline Ileus & $2(1.7 \%)$ & 0 & 0 \\
\hline $\begin{array}{l}\text { Abdominal wall } \\
\text { erythema }\end{array}$ & 0 & $1(<1 \%)$ & 0 \\
\hline $\begin{array}{l}\text { Application site } \\
\text { blister }\end{array}$ & $1(<1 \%)$ & 0 & 0 \\
\hline
\end{tabular}

\footnotetext{
${ }^{\text {a }}$ Perioperative complications occurred up to 14 days after surgery
} 
likely related to a transfascial fixation suture near the costal margin. While this patient was not seen back for 1-year follow-up, the patient had not (as of the postoperative visit following mesh removal) developed a recurrent hernia. One patient developed a superficial wound infection which was treated with antibiotics and resolved.

There were 5 complications that occurred in 4 patients in the early postoperative period ranging from 2 weeks to 6 months after surgery. One patient developed an infected seroma 3 months postoperatively requiring operative drainage. At that time, the mesh was removed as it was in the field of an infected fluid collection. One patient developed an intraabdominal abscess, which was treated with antibiotics and resolved. There were no late complications that occurred in patients between 6 and 12 months after surgery. In total, 99 patients were seen in 1-year follow-up. All patients underwent physical exam which did not detect any evidence of hernia recurrences (95\% CI 0-4\%).

Of the recorded adverse events, investigating surgeons implicated the mesh as possibly or definitely related to the mesh in three instances. One patient who developed a postoperative hematoma at the surgical site was felt to possibly be related to the device and definitely related to the procedure. A second patient with postoperative seroma was definitely felt to be related to both the device and the procedure and hernia repair site pain which was felt to be possibly related to the surgical procedure. A third patient with transitory erythema of the abdominal wall was definitely felt to be related to both the device and the procedure. The remainder of the adverse events was felt to be related to the procedure or not related to either the mesh or the procedure.

Carolinas Comfort Scale surveys were satisfactorily completed (with fewer than 2 missing questions) for inclusion in the study by 111 by patients at the initial preoperative visit, by 116 patients at the first 2-week postoperative visit, by 108 patients at the 6-month postoperative visit, and by 98 patients at 1 year following hernia repair. Results of patient reported symptoms for each activity in the areas of mesh sensation, pain, and movement limitation are indicated in Table 5. Reflective in Fig. 1 is the change in mean pain, sensation of mesh, and movement limitation scores which all declined over the 1-year time period. By 4 weeks postoperatively, $87.8 \%$ of patients had returned to normal daily activity. By 7 weeks time, $72.4 \%$ had returned to strenuous or vigorous activity. Of those patients working, by 4 weeks, $86.0 \%$ were able to return to work. Summarized in Table 6 are times to return to work and activity for 98 patients who completed this portion of the questionnaire at a single postoperative visit.

\section{Discussion}

The invention of many new synthetic materials has allowed for different types of prosthetic grafts to be used in hernia repair. In the 1950s, polypropylene mesh was first developed by Dr. Francis Usher. Its use in hernia repair was found to be associated with low hernia recurrence rate. This design was modified into a knitted construct in the 1960s which has served as the basis for most prosthetic meshes in the twentieth century [8]. Original polypropylene meshes consisting of dense "heavyweight" material were occasionally associated with significant inflammatory reactions eventually leading to mesh shrinkage and loss of abdominal wall compliance [9]. Newer generation "lightweight" polypropylene mesh caused decreased inflammatory reaction leading to improved abdominal wall compliance while still providing adequate tissue ingrowth $[10,11]$.

Polypropylene mesh, however, may not represent the most ideal mesh for intraperitoneal placement. While short-term follow-up studies have demonstrated the safety of polypropylene mesh when adjacent to bowel [12], multiple studies and case reports have described concerning problems when polypropylene mesh is placed intraperitoneal or adjacent to bowel. Reported findings include intense intraabdominal adhesion formation, intestinal erosions, and enterocutaneous fistulas [13-17].

The response to associated problems seen with polypropylene mesh was the creation of a combination of materials designed to meet the varying challenges of intraabdominal placement against different surfaces, visceral, and parietal. Composite mesh prostheses contain

Table 5 Mean Carolinas Comfort Scale Scores with change

\begin{tabular}{llcccc}
\hline & Baseline & 2 weeks & 6 months & 1 year & Mean $\Delta$ baseline to 1 year \\
\hline $\mathrm{N}$ & 111 & 116 & 108 & 99 & N/A \\
Pain & 1.3 & 1.6 & 0.3 & 0.3 & 1.1 \\
Sensation of mesh & N/A & 0.7 & 0.2 & 0.1 & 0.6 \\
Movement limitation & 1.1 & 1.4 & 0.1 & 1.0 \\
\hline
\end{tabular}

$N=$ number of patient questionnaires and scores used to calculate values at each of the interval time periods 
Fig. 1 Change in mean Carolinas Comfort Scale scores for pain, mesh sensation, and movement limitations over the course of patient follow-up

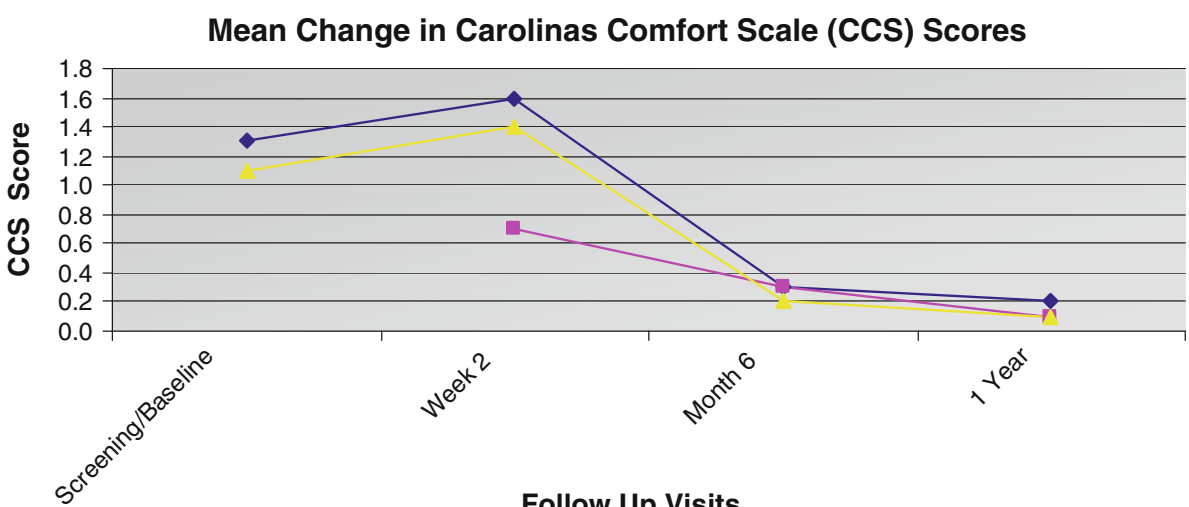

Follow Up Visits

$\multimap$ Pain $\longrightarrow$ Sensation of Mesh $\longrightarrow \_$Movement limitations

Table 6 Duration to return to physical activity

\begin{tabular}{lrr}
\hline$N=98$ patients who completed this portion of & $N$ \\
questionnaire & & \\
\hline Duration to return to normal, daily activity & 61 & 62.2 \\
Less than 1 week up to 2 weeks & 25 & 25.5 \\
2-4 weeks & 12 & 12.2 \\
4-8 weeks & & \\
Duration to return to more vigorous or strenuous activity & 30 & 30.6 \\
Less than 3 weeks & 41 & 41.8 \\
3-7 weeks & 11 & 11.2 \\
7-11 weeks & 5 & 5.1 \\
More than 11 weeks & 11 & 11.2 \\
Not applicable & & \\
Duration to return to work & 18 & 18.4 \\
Less than 3 weeks & 19 & 19.4 \\
3-7 weeks & 6 & 6.1 \\
7-9 weeks & 55 & 56.1 \\
Not applicable & & \\
Patient's physical job requirements & 14 & 14.3 \\
Minimal physical requirements & 17 & 17.3 \\
Moderate physical requirements & 13 & 13.3 \\
Heavy physical requirements & 54 & 55.1 \\
Not applicable/not employed &
\end{tabular}

both macroporous, for example, polypropylene, and microporous, for example, expanded polytetrafluoroethylene (ePTFE), components or absorbable barriers such as polyethylene glycol (PEG), hyaluronic acid, and carboxymethylcellulose (CMC) [18]. The polypropylene material on the parietal mesh surface causes a local inflammatory response that promotes host tissue in-growth, while the visceral barrier material acts to protect underlying viscera $[19,20]$. In vivo animal studies confirm the rapid tissue ingrowth obtained with composite polypropylene/ePTFE mesh at 2 weeks (74\% of total shear strength seen at 12 weeks) [21, 22]. This combination and selective positioning of polypropylene and ePTFE materials allows for manipulation of the host inflammatory response to favor rapid mesh incorporation at the parietal surface while suppressing complications that result from contact with abdominal viscera. Furthermore, multiple clinical studies have demonstrated the efficacy and safety of composite mesh materials used for ventral hernia repair [23-25].

One such composite mesh, Composix Kugel (C.R. Bard; Davol Inc. Warick, RI), combined two layers of monofilament polypropylene and a third layer of PTFE with a selfexpanding ring to aid in the placement and positioning of the mesh intraabdominally. The Composix Kugel technique places the graft in a sublay position and does not require the development of subcutaneous flaps. Fixation occurs with both tacks and transfascial sutures. The results from a large series, prospective trial examining outcomes of this technique were published in 2008. During the 5-year study period, this composite mesh and hernia repair technique were associated with a low rate of hernia recurrence (1\% with an average follow-up of 29.3 months) and low rate of early and late infection (1 and $0.4 \%$ ) [25]. Additional, small series studies have demonstrated the efficacy and safety of this composite hernia patch using an intraperitoneal onlay technique in the repair of flank abdominal bulge [26] and inguinal hernias [27].

The Ventrio ${ }^{\mathrm{TM}}$ Hernia Patch (Bard Davol, Inc. Warick, RI) was chosen for this study as it represents a composite mesh with a memory ring. Using similar techniques of the Composix Kugel Patch, it is a round or oval-shaped graft that combines three layers of synthetic material with an absorbable polydioxanone (PDO) ring that aids in positioning and intraabdominal placement (Fig. 2). The parietal surface consists of a double layer of lightweight, large pore polypropylene with a central opening creating a pocket to allow for tack fixation peripherally. The visceral side is made of ePTFE. The most novel component is an absorbable PDO monofilament incorporated at the periphery of the mesh for placement and fixation. In the Ventrio ${ }^{\mathrm{TM}}$ 

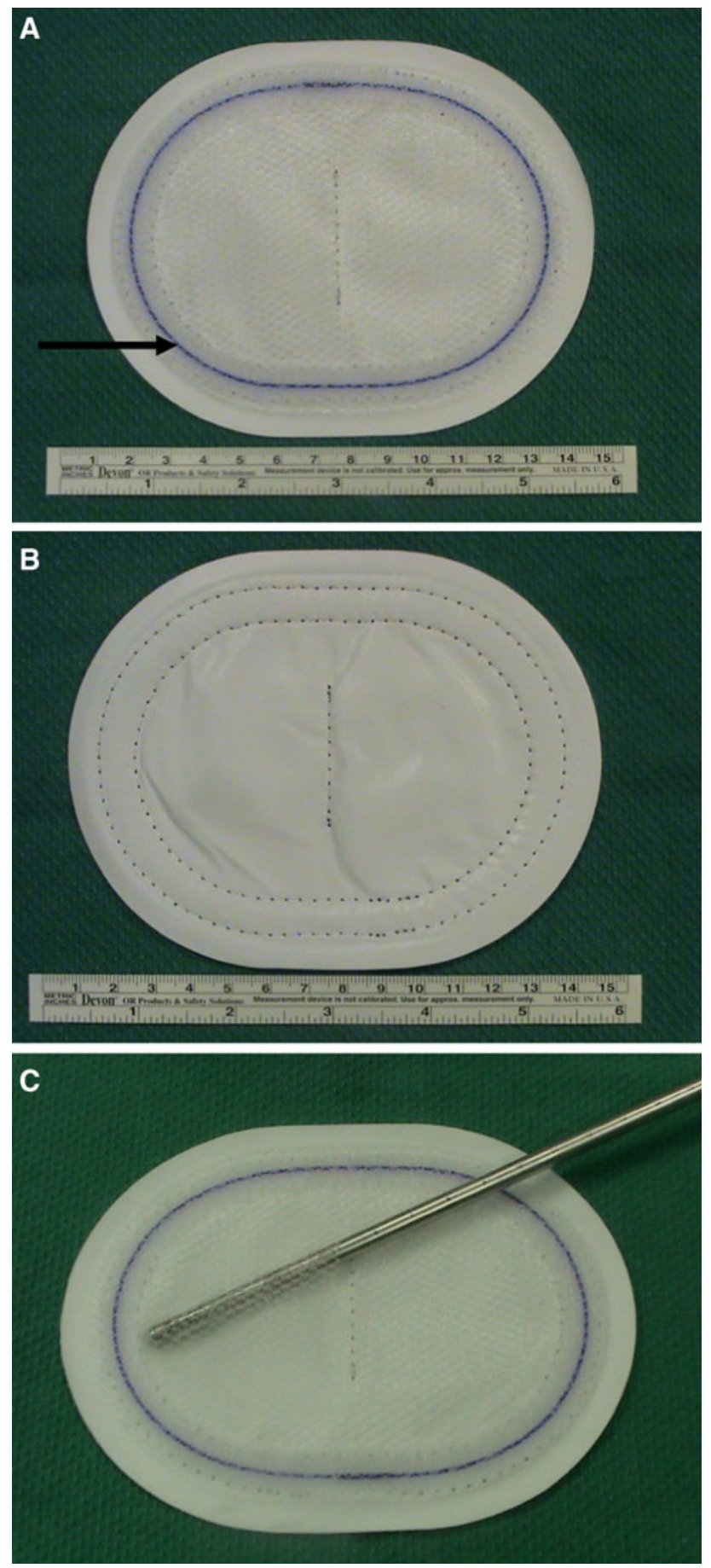

Fig. 2 Ventrio ${ }^{\mathrm{TM}}$ Hernia Patch. a polypropylene surface with internalized, absorbable polydioxanone (PDO) ring (arrow), b expanded polytetrafluoroethylene (ePTFE) surface, c fixation device placed between the polypropylene bi-layer fixation pocket

Hernia Patch, this PDO ring allows the flexible mesh to return to a flat position against the abdominal wall facilitating optimal positioning. Since the memory function is no longer necessary after the mesh is secured to the abdominal wall, the ring undergoes hydrolysis in vivo and is absorbed
[29]. In effect, this decreases the amount of foreign material that remains in the abdomen over time.

In a preclinical study, this graft demonstrated a capacity for strong integration of host tissues while limiting intraabdominal adhesion formation in a porcine model of open ventral hernia repair. Histological evaluation showed a progressive increase in the presence of vascular structures following implantation. No adhesions were present in $50 \%$ of grafts explanted at 8 weeks. Tensiometric evaluation revealed progressive absorption of the PDO ring after implantation with complete mechanical degradation of the ring by 12 weeks [28]. Full resorption of the PDO ring material is essentially complete by $24-32$ weeks.

Our study confirms findings seen similar to the Ventrio ${ }^{\mathrm{TM}}$ Hernia Patch's progenitor of low rates of hernia recurrence and minimal risk of infection. The low infection rate seen likely is the result of multiple factors including surgical technique, coverage of the mesh, small incision, and selective drain placement. While drain placement in open ventral hernia repair has been associated with the development of wound infections [29], neither of the patients who developed wound infections had drains placed at the time of surgery. Other factors in these patients including obesity, smoking, and presence of significant medical comorbidities may have contributed to the development of postoperative surgical site infection. In this series, no hernia recurrences were seen in the 1-year time period. Significant mesh overlap was noted as mean defect size was $13.6 \mathrm{~cm}^{2}$ while mean mesh size used for defect coverage was $113.6 \mathrm{~cm}^{2}$ which gives a ratio of mesh coverage to defect size of $8.4 \mathrm{~cm}^{2}$.

Improved clinical outcomes have been seen with the use of tension free mesh repair techniques in ventral hernia repair $[4,5]$. As a result, the evaluation of quality of life prior to and following ventral hernia repair is important in understanding the impact surgical treatment has on the medical condition and benefit perceived by patients. A general measurement of surgical outcomes can be obtained with the Medical Outcomes Study 36-Item Short-Form Health Survey (SF-36). However, prior studies have demonstrated that disease-specific questionnaires are more useful than general questionnaires in the evaluation of patient symptom severity and changes caused by surgical treatment $[30,31]$. The Carolinas Comfort Scale (CCS), developed at Carolinas Medical Center, is a disease-specific questionnaire that accurately reflects patient satisfaction following hernia repair and quality of life. As compared to the SF-36, the CCS was found to better predict patient-perceived symptoms and satisfaction following hernia repair [7]. These findings were replicated in a follow-up study in which the CCS was more sensitive than the SF-36 in detecting change in patients' quality of life following laparoscopic versus open ventral hernia repair [32]. 
In this investigation, improvement in CCS scores can be defined from the basis of an overall average improved change in symptoms related to the patient's ventral hernia. At baseline, an average pain score of 1.3 correlates to mild symptoms bothersome in some patients. This value declined to 0.2 at the conclusion of the study period with a value of zero corresponding to no symptoms at all. Similar improvement was noted in patients' mean movement limitation scores which declined well beyond the baseline prior to hernia repair. The mean change in sensation of mesh score also improved from 2 weeks following surgery to 1-year follow-up visits. The majority of patients in this study had returned to normal daily activity by 4 weeks following surgery and by 7 weeks after surgery had resumed vigorous or strenuous activity. Statistical analysis of pre- and postoperative CCS scores was not performed as post hoc analyses would not be appropriate to make inferences regarding the statistical significance of these values. While a decline was clearly indicated in the descriptive results of CCS scoring pre- and post-intervention, a more sufficiently powered study with control group would be required to provide an accurate comparative analysis.

This study is strengthened by its multi-institutional design. While a common surgical repair technique was agreed upon and utilized in this series, slight differences in surgical practice between surgeons and institutions are more reflective of practicing surgeons than would be seen in a single surgeon series. The surgeons participating in this study are highly experienced in this type of hernia repair technique with a large volume of clinical experience.

In summary, this study demonstrates that the use of a second-generation composite mesh for open ventral hernia repair results in low rate of perioperative and early complications with no hernia recurrence seen in the 1-year study period. Patients overall had excellent outcomes with improvement in mean pain and movement limitation scores from baseline values. Sensation of mesh scores also improved from 2 weeks postoperative to 1-year follow-up time points. The absorbable PDO ring assists the surgeons with placement and fixation of the mesh but has the added benefit of dissolving over time, decreasing the amount of foreign material left in the body. Overall findings from this investigation are based on an observational study design with $83 \%$ follow-up of patients at 1-year post-surgery. Further studies are needed to follow-up long-term results to confirm the low rate of hernia recurrence and additional long-term complications with this composite mesh.

Conflict of interest C. R. Bard, Inc. (Davol Inc.) was the sponsor of this study and provided data management services.

Iannitti, Millikan, Moskowitz are consultants for Davol Inc.

Erin M. Hanna declares no conflict of interest; Jim F. Byrd declares no conflict of interest; Mark Moskowitz declares having received funds in relation to this study; Kurt T. Stockamp declares having received funds in relation to this study; Michael A. Beneke declares no conflict of interest that directly relates to this study but having received funds from the study sponsor for activities outside of this work; Keith Millikan declares no conflict of interest that directly relates to this study but having received funds from the study sponsor for activities outside of this work; David A. Iannitti declares having received institutional support in relation to this study.

Dr. John WF Mann declares having received funds in relation to this study. Dr. Gavish N. Patel declares having received institutional support in relation to this study.

Open Access This article is distributed under the terms of the Creative Commons Attribution Noncommercial License which permits any noncommercial use, distribution, and reproduction in any medium, provided the original author(s) and the source are credited.

\section{References}

1. Mudge M, Hughes LE (1985) Incisional hernia: a 10 year prospective study of incidence and attitudes. Br J Surg 72:70-71

2. Sorensen LT, Hemmingsen UB, Kirkeby LT, Kallehave F, Jorgensen LN (2005) Smoking is a risk factor for incisional hernia. Arch Surg 140:119-123

3. Read RC, Yoder G (1989) Recent trends in the management of incisional herniation. Arch Surg 124:485-488

4. Burger JW, Luijendijk RW, Hop WC, Halm JA, Verdaasdonk EG, Jeekel J (2004) Long-term follow-up of a randomized controlled trial of suture versus mesh repair of incisional hernia. Ann Surg 240:578-583; discussion 583-575

5. Luijendijk RW, Hop WC, van den Tol MP, de Lange DC, Braaksma MM, IJzermans JN, Boelhouwer RU, de Vries BC, Salu MK, Wereldsma JC, Bruijninckx CM, Jeekel J (2000) A comparison of suture repair with mesh repair for incisional hernia. N Engl J Med 343:392-398

6. Millikan KW (2003) Incisional hernia repair. Surg Clin North Am 83:1223-1234

7. Heniford BT, Walters AL, Lincourt AE, Novitsky YW, Hope WW, Kercher KW (2008) Comparison of generic versus specific quality-of-life scales for mesh hernia repairs. J Am Coll Surg 206:638-644

8. Usher FC (1963) Hernia repair with knitted polypropylene mesh. Surg Gynecol Obstet 117:239-240

9. Cobb WS, Kercher KW, Heniford BT (2005) The argument for lightweight polypropylene mesh in hernia repair. Surg Innov 12: 63-69

10. Klinge U, Klosterhalfen B, Muller M, Schumpelick V (1999) Foreign body reaction to meshes used for the repair of abdominal wall hernias. Eur J Surg 165:665-673

11. Cobb WS, Burns JM, Peindl RD, Carbonell AM, Matthews BD, Kercher KW, Heniford BT (2006) Textile analysis of heavy weight, mid-weight, and light weight polypropylene mesh in a porcine ventral hernia model. J Surg Res 136:1-7

12. Vrijland WW, Jeekel J, Steyerberg EW, Den Hoed PT, Bonjer HJ (2000) Intraperitoneal polypropylene mesh repair of incisional hernia is not associated with enterocutaneous fistula. Br J Surg $87: 348-352$

13. Halm JA, de Wall LL, Steyerberg EW, Jeekel J, Lange JF (2007) Intraperitoneal polypropylene mesh hernia repair complicates subsequent abdominal surgery. World J Surg 31:423-429; discussion 430

14. Jenkins ED, Yom V, Melman L, Brunt LM, Eagon JC, Frisella MM, Matthews BD (2010) Prospective evaluation of adhesion characteristics to intraperitoneal mesh and adhesiolysis-related 
complications during laparoscopic re-exploration after prior ventral hernia repair. Surg Endosc 24:3002-3007

15. Nicolson A, Adeyemo D (2009) Colovaginal fistula: a rare longterm complication of polypropylene mesh sacrocolpopexy. J Obstet Gynaecol 29:444-445

16. Farmer L, Ayoub M, Warejcka D, Southerland S, Freeman A, Solis M (1998) Adhesion formation after intraperitoneal and extraperitoneal implantation of polypropylene mesh. Am Surg 64:144-146

17. Morris-Stiff GJ, Hughes LE (1998) The outcomes of nonabsorbable mesh placed within the abdominal cavity: literature review and clinical experience. J Am Coll Surg 186:352-367

18. Deeken CR, Faucher KM, Matthews BD (2011) A review of the composition, characteristics, and effectiveness of barrier mesh prostheses utilized for laparoscopic ventral hernia repair. Surg Endosc 26:566-575

19. White RA (1988) The effect of porosity and biomaterial on the healing and long-term mechanical properties of vascular prostheses. ASAIO Trans 34:95-100

20. Amid P (1997) Classification of biomaterials and their related complications in abdominal wall hernia surgery. Hernia 1:15-21

21. Majercik S, Tsikitis V, Iannitti DA (2006) Strength of tissue attachment to mesh after ventral hernia repair with synthetic composite mesh in a porcine model. Surg Endosc 20:1671-1674

22. Iannitti DA, Hope WW, Tsikitis V (2007) Strength of tissue attachment to composite and ePTFE grafts after ventral hernia repair. JSLS 11:415-421

23. Bendavid R (1997) Composite mesh (polypropylene-e-PTFE) in the intraperitoneal position. A report of 30 cases. Hernia 1:5-8
24. Cobb WS, Harris JB, Lokey JS, McGill ES, Klove KL (2003) Incisional herniorrhaphy with intraperitoneal composite mesh: a report of 95 cases. Am Surg 69:784-787

25. Iannitti DA, Hope WW, Norton HJ, Lincourt AE, Millikan K, Fenoglio ME, Moskowitz M (2008) Technique and outcomes of abdominal incisional hernia repair using a synthetic composite mesh: a report of 455 cases. J Am Coll Surg 206:83-88

26. Liu FD, Li JY (2011) Surgical repair of the abdominal bulge using composix kugel patch with the intraperitoneal onlay mesh technique. Plast Reconstr Surg 128:103e-104e

27. Takayama S, Sakamoto M, Takeyama H (2010) Laparoscopic inguinal hernia repair with the Composix Kugel Patch. Int Surg 95:54-56

28. Byrd JF, Agee N, Nguyen PH, Heath JJ, Lau KN, McKillop IH, Sindram D, Martinie JB, Iannitti DA (2011) Evaluation of composite mesh for ventral hernia repair. JSLS 15:298-304

29. Kaafarani HM, Kaufman D, Reda D, Itani KM (2010) Predictors of surgical site infection in laparoscopic and open ventral incisional herniorrhaphy. J Surg Res 163:229-234

30. Urbach DR (2005) Measuring quality of life after surgery. Surg Innov 12:161-165

31. Velanovich V (1998) Comparison of generic (SF-36) vs. diseasespecific (GERD-HRQL) quality-of-life scales for gastroesophageal reflux disease. J Gastrointest Surg 2:141-145

32. Hope WW, Lincourt AE, Newcomb WL, Schmelzer TM, Kercher KW, Heniford BT (2008) Comparing quality-of-life outcomes in symptomatic patients undergoing laparoscopic or open ventral hernia repair. J Laparoendosc Adv Surg Tech A 18:567-571 